Argonne Rational Laboratom

ON THE STEADY-STATE THERMAL STRESSES

IN CYLINDRICAL FUEL PINS DUE TO

AXIAL VARIATIONS IN THEIR

INTERNAL HEAT-GENERATION RATE

$$
\text { by }
$$

Richard A. Valentin 


\section{DISCLAIMER}

This report was prepared as an account of work sponsored by an agency of the United States Government. Neither the United States Government nor any agency Thereof, nor any of their employees, makes any warranty, express or implied, or assumes any legal liability or responsibility for the accuracy, completeness, or usefulness of any information, apparatus, product, or process disclosed, or represents that its use would not infringe privately owned rights. Reference herein to any specific commercial product, process, or service by trade name, trademark, manufacturer, or otherwise does not necessarily constitute or imply its endorsement, recommendation, or favoring by the United States Government or any agency thereof. The views and opinions of authors expressed herein do not necessarily state or reflect those of the United States Government or any agency thereof. 


\section{DISCLAIMER}

Portions of this document may be illegible in electronic image products. Images are produced from the best available original document. 
The facilities of Argonne National Laboratory are owned by the United States Government. Under the terms of a contract (W-31-109-Eng-38) between the U. S. Atomic Energy Commission, Argonne Universities Association and The University of Chicago, the University employs the staff and operates the Laboratory in accordance with policies and programs formulated, approved and reviewed by the Association.

\section{MEMBERS OF ARGONNE UNIVERSITIES ASSOCIATION}

The University of Arizona Carnegie Institute of Technology

Case Institute of Technology

The University of Chicago

University of Cincinnati

Illinois Institute of Technology

University of Illinois

Indiana University

Iowa State University
The University of Iowa Kansas State University The University of Kansas Loyola University Marquette University Michigan State University The University of Michigan University of Minnesota University of Missouri
Northwestern University University of Notre Dame The Ohio State University Purdue University Saint Louis University Washington University Wayne State Univer sity The University of Wisconsin

\section{LEGAL NOTICE}

This report was prepared as an account of Government sponsored work. Neither the United States, nor the Commission, nor any person acting on behalf of the Commission:

A. Makes any warranty or representation, expressed or implied, with respect to the accuracy, completeness, or usefulness of the information contained in this report, or that the use of any information, apparatus, method, or process disclosed in this report may not infringe privately owned rights; or

B. Assumes any liabilities with respect to the use of, or for damages resulting from the use of any information, apparatus, method, or process disclosed in this report.

As used in the above, "person acting on behalf of the Commission" includes any employee or contractor of the Commission, or employee of such contractor, to the extent that such employee or contractor of the Commission, or employee of such contractor prepares, disseminates, or provides access to, any information pursuant to his employment or contract with the Commission, or his employment with such contractor.

Printed in the United States of America

Available from

Clearinghouse for Federal Scientific and Technical Information

National Bureau of Standards, U. S. Department of Commerce

Springfield, Virginia 22151

Price: Printed Copy $\$ 3.00$; Microfiche $\$ 0.65$ 
ON THE STEADY-STATE THERMAL STRESSES

IN CYLINDRICAL FUEL PINS DUE TO

AXIAL VARIATIONS IN THEIR

INTERNAL HEAT-GENERATION RATE

by

Richard A. Valentin

Reactor Engineering Division

н.с. $3.00 ; \mathrm{MN} .65$

December 1966

LEGL NOTICE LE A A Government sponsored work. Nomission:

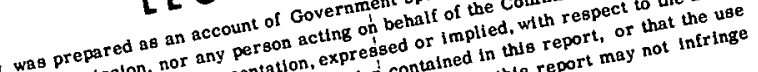

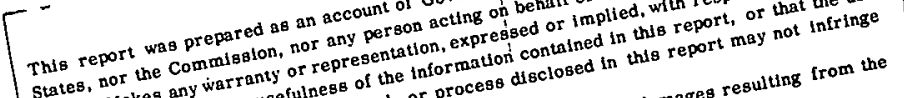
A. Makes any or usefulness method, or proces, of or for damages resul.

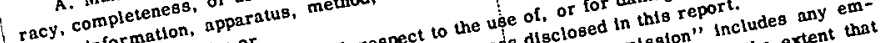
of any inform rights: or whes with respect process dlsclo commalsston" to the extent that privately owned any liablilies wh, method, of behall of the con contractor, ntactor prepares.

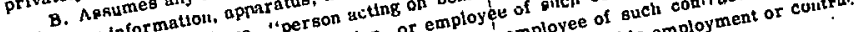
use of any inform the above. pommission, or caton, or employee to his employ

As used in thetor of the com the commisermation purguant

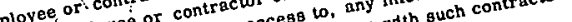

such employee or provides access toyment with such cons such eminates, or provid or hls employ

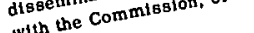


TAB LE OF CONTENTS

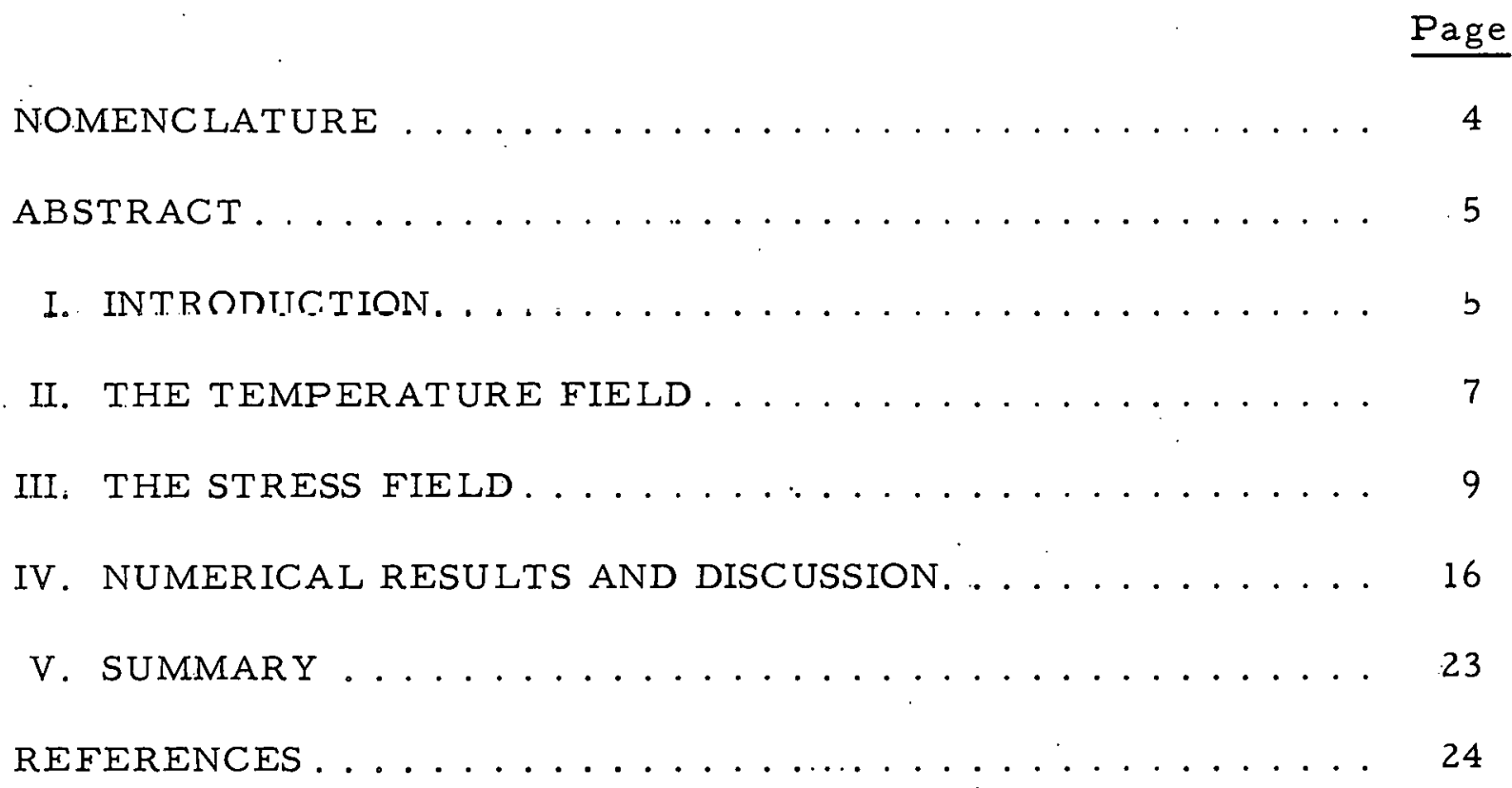




\section{LIST OF FIGURES}

No.

Title

Pàge

1. Coordinate System and Axial Heat-generation Profile...... 6

2. Axial Temperature Profiles $(\beta=4.0) \ldots \ldots \ldots 17$

3. Radial Stress at Cylinder Centerline $(\beta=4.0, \nu=0.25, \rho=0.0) . \quad 17$

4. Axial Stress at Cylinder Surface $(\beta=4.0, \nu=0.25, \rho=1.0)$. . : 18

5. Circumferential Stress at Cylinder Surface $(\beta=4.0, \nu=0.25$,

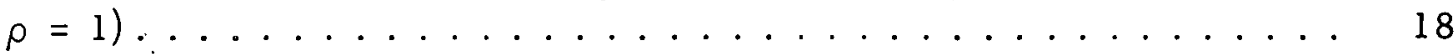

6. Shear Stress at $\rho=0.5(\beta=4.0, \nu=0.25) \ldots \ldots 18$

7. Radial Displacement of Cylinder Surface $(\beta=4.0) \ldots \ldots$

8. Effect of Poisson's Ratio on Axial and Circumferential Stress at Cylinder Surface $(m=1.0, \beta=4.0) \ldots \ldots \ldots$

9. Effect of Poisson's Ratio on Radial Stress at Cylinder Centerline $(\mathrm{m}=1.0, \beta=4.0) \ldots \ldots \ldots$

10. Effect of Poisson's Ratio on Shear Stress at $\rho=0.5(\beta=4.0$, $\mathrm{m}=1.0) \ldots \ldots \ldots \ldots \ldots$

11. Radial Stress at Cylinder Centerline $(\beta=1.0, \nu=0.25, \rho=0.0)$.

12. Axial Stress at Cylinder Surface and Cylinder Centerline $(\beta=$ $1.0, \nu=0.25) \ldots \ldots \ldots \ldots \ldots$

13. Circumferential Stress at Cylinder Surface $(\beta=1.0, \nu=0.25$, $\rho=1$ )

14. Effect of Ramp Decrease in Heat Generation on Radial Stress at Cylinder Centerline $(\rho=0.0, \beta=4.0, \nu=0.25, \mathrm{~m}=0.1) \ldots$

15. Effect of Ramp Decrease in Heat Generation on Axial Stress at Cylinder Surface $(\rho=1.0, \beta=4.0, \nu=0.25, \mathrm{~m}=0.1) \ldots \ldots$

16. Effect of Ramp Decrease in Heat Generation on Circumferential Stress at Cylinder Surface $(\rho=1.0, \beta=4.0, \nu=0.25$, $\mathrm{m}=0.1) \ldots \ldots \ldots \ldots \ldots$

17. Effect of Ramp Decrease in Heat Generation on Shear Stress at $\rho=0.5(\beta=4.0, \nu=0.25, m=0.1) \ldots \ldots$ 
NOMENCLATURE 
a

$\mathrm{E}$

h

$I_{0}, I_{1}$

k

L

m

$\mathrm{p}$

q

Q

$Q_{1}$

r

$\mathrm{T}, \mathrm{T}_{1}$

$\hat{\mathrm{T}}$

$\hat{\mathrm{T}}_{0}$

$\mathrm{u}, \mathrm{w}$

z

$\alpha$

$\beta$

$\epsilon$

$\zeta$

$\kappa$

$\nu$

$\rho$

$\sigma_{\rho \rho}, \sigma_{\rho \zeta}$, etc

$\phi$

$\Omega, \Phi$

$\hat{\Omega}, \hat{\Phi}$ cylinder radius

Young's modulus of cylinder

film conductance at cylinder surface

zéro and first-order modified Bessel functions

conductivity of cylinder

average neutron-diffusion length

Biot number

transform variable or variable of integration

internal heat-generation rate

constant heat-generation rate

dimensionless constant heat-generation rate

radial coordinate

dimensionless temperatures

cylinder temperature

constant temperature of medium surrounding cylinder

radial and axial displacement functions

axial coordinate

thermal-expansion coefficient of cylinder

half axial length of constant heat generation (Fig. 1)

axial length of ramp decrease in heat generation (Fig. 1)

dimensionless axial coordinate

dimensionless inverse average neutron-diffusion length

Poisson's ratio of cylinder

dimensionless radial coordinate

dimensionless stresses

thermal-neutron flux.

dimensionless Hoyle stress functions

Hoyle stress functions 


\title{
ON THE STEADY-STATE THERMAL STRESSES \\ IN CYLINDRICAL FUEL PINS DUE TO \\ AXIAL VARIATIONS IN THEIR \\ INTERNAL HEAT-GENERATION RATE
}

by

\author{
Richard $\Lambda$. Valentin
}

\begin{abstract}
The thermal-stress field in a heat-generating circular cylinder, which is free of external tractions and being cooled by a temperature-independent boundary conductance, is studied within the framework of classical elasticity to determine the effects of abrupt axial changes in the heatgeneration profile. Heat-generation rates having both axial jumps and axial ramp changes have been considered, and the integral expressions for the stress and displacement fields evaluated for a wide range of Biot numbers. These evaluations provide a detailed qualitative picture of the resulting stress state and, in addition, demonstrate that the stresses are relatively insensitive to the rate of change of the axial heat generation; the results for discontinuous changes differ only slightly from those for ramp changes. Also, with the exception of the shear stress, the magnitudes of the various stresses in the neighborhood of such abrupt axial changes are not significantly larger than those one would compute using a uniform heat-generation rate and neglecting all axial effects.
\end{abstract}

\section{INTRODUCTION}

In the steady-state operation of a heterogeneous thermal reactor whose core consists of an array of cylindrical fuel pins, we can conceive of several situations in which an individual pin experiences a rather abrupt axial change in its internal heat-generation rate. For example, when a strong bank of control rods is partially inserted into the core, the resulting distortion of the flux near the control-rod tips may produce an abrupt axial decrease in the heat-generation rate and, in turn, produce large axial temperature gradients. A similar temperature gradient would occur if manufacturing error produced a fuel pin which, over a small segment of its length, had an appreciably higher than average fuel concentration. 
The problem to be considered concerns the effect of such axial temperature gradients on the local thermal-stress field in the fuel pin and is an attempt to provide at least a qualitative picture of how sensitive this field is to the various details of the axial heat-generation profile. In particular, we are interested in whether the various stress components in the neighborhood of an abrupt axial change in heat generation are significantly larger than those one would compute using a uniform heating rate equal to the maximum existing rate and neglecting all axial effects. Also, it is of interest to determine whether the assumption of an axial jump in the internal heat-generation rate produces stress values significantly different from those due to a ramp change in the rate.

Specifically, we shall be concerned with the case of a solid right circular cylinder of infinite axial extent, having a stress-free outer bound-
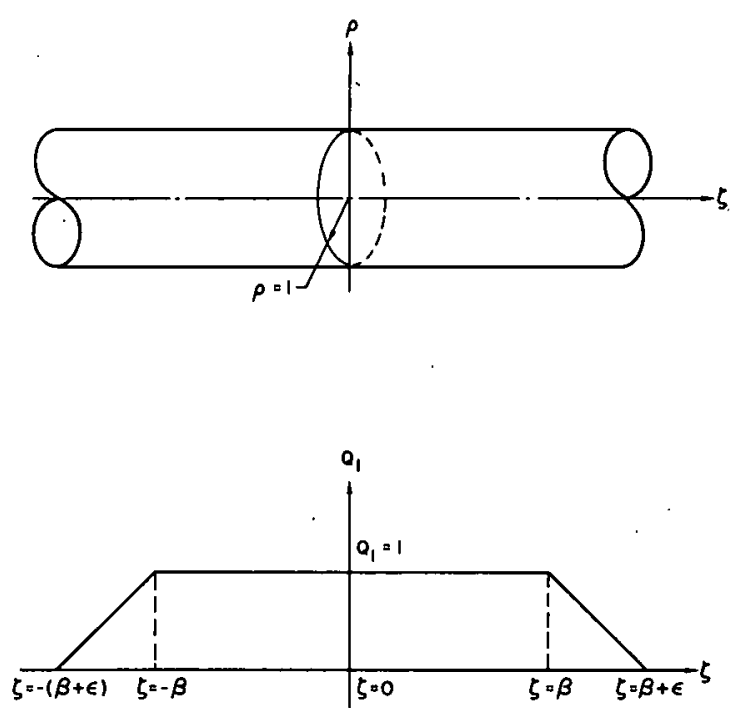

Fig. 1. Coordinate System and Axial Heatgeneration Profile ary, being cooled by a temperatureindependent boundary conductance, and having an axial heat-generation rate of the form shown in Fig. 1. By varying the length of the region of uniform heat generation and the slope of the ramp decrease in generation, we obtain a wide variety of approximations applicable to the types of problem mentioned above. Several of the assumptions we have made to produce an analytically tractable problem are such that the final results may not be directly applicable to specific design problems. In particular, the assumption of a temperature-independent boundary conductance is not reasonable in most actual situations. It is felt, however, that assumptions of this nature are both a reasonable and necessary first step in isolating the axial effects that are our primary concern. In addition, the solutions obtained provide a convenient set of exact results with which to check the accuracy of elaborate computer stress-analysis programs, which are able to handle more realistic conditions.

As yet we have made no reference to possible radial dependence of the internal heat-generation rate. For example, it is known that the radial variation of thermal-neutron density (and hence heat generation) within a fuel rod such as those with which we are concerned is closely approximated by

$$
\phi=A I_{0}\left(\frac{r}{L}\right)
$$


where $A$ is a constant and $L$ is an average neutron-diffusion length (e.g., see Bonilla, ${ }^{1}$ p. 366). The inclusion of a radial dependence proportional to $I_{0}(r / L)$ is only a minor complication in solving the required heat-transfer problem and, for reference, has been included in the solution for the temperature field to be found in Section II below. For the stress field, however, such a term greatly increases the complexity of the solution and is not included here. In effect, we are assuming that $L$ is large relative to the radius, a, of the fuel pin and, hence, that the radial heat generation is given by the first term in the small argument expansion of $I_{0}[(a / L) \rho]$; that is, that the generation is constant across the radius.

\section{THE TEMPERATURE FIELD}

We consider an infinite circular cylinder of radius a, whose heatgeneration rate is given by.

$$
q(r, z)=I_{0}\left(\frac{r}{L}\right) f(z)
$$

where

$$
f(z)= \begin{cases}Q, & 0 \leq|z| \leq b ; \\ \frac{Q}{c}(b+c-|z|), & b \leq|z| \leq b+c ; \\ 0, & b+c \leq|z|<\infty .\end{cases}
$$

The cylinder transfers heat through a constant film conductance, $h$, to a medium at temperature $\hat{\mathrm{T}}_{0}$. Thus, the temperature field satisfies

$$
\begin{aligned}
& \mathrm{k}\left(\frac{\partial^{2} \hat{\mathrm{T}}}{\partial \mathrm{r}^{2}}+\frac{1}{\mathrm{r}} \frac{\partial \hat{\mathrm{T}}}{\partial \mathrm{r}}+\frac{\partial^{2} \hat{\mathrm{T}}}{\partial z^{2}}\right)+\mathrm{f}(\mathrm{z}) \mathrm{I}_{0}\left(\frac{\mathrm{r}}{\mathrm{L}}\right)=0, \quad\left\{\begin{array}{l}
-\infty<\mathrm{z}<\infty \\
0 \leq \mathrm{r} \leq \mathrm{a}
\end{array}\right\}, \\
& \mathrm{k}\left(\frac{\partial \hat{\mathrm{T}}}{\partial \mathrm{r}}\right)_{\mathrm{r}=\mathrm{a}}=\mathrm{h}\left[\hat{\mathrm{T}}_{0}-\hat{\mathrm{T}}(\mathrm{a} ; \mathrm{z})\right], \quad-\infty<\mathrm{z}<\infty,
\end{aligned}
$$

where $\mathrm{k}$ is the conductivity of the cylinder. If we introduce dimensionless quantities as follows:

$$
\begin{aligned}
& \hat{\mathrm{T}}=\hat{\mathrm{T}}_{0}\left(1-Q_{1} \mathrm{~T}\right), \quad Q_{1}=\frac{\mathrm{Qa}^{2}}{\mathrm{k \hat { \textrm {T } } _ { 0 }},} \\
& \zeta=\frac{\mathrm{z}}{\mathrm{a}}, \quad \rho=\frac{\mathrm{r}}{\mathrm{a}}, \quad \beta=\frac{\mathrm{b}}{\mathrm{a}}, \quad \epsilon=\frac{\mathrm{c}}{\mathrm{a}}, \quad \kappa=\frac{\mathrm{a}}{\mathrm{L}},
\end{aligned}
$$


Eqs. (1) becomes

$$
\begin{array}{ll}
\nabla^{2} \mathrm{~T} \equiv \frac{\partial^{2} \mathrm{~T}}{\partial \rho^{2}}+\frac{1}{\rho} \frac{\partial \mathrm{T}}{\partial \rho}+\frac{\partial^{2} \mathrm{~T}}{\partial \zeta^{2}}=\mathrm{f}_{1}(\zeta) \mathrm{I}_{0}(\kappa \rho), & \left\{\begin{array}{l}
-\infty<\zeta<\infty \\
0 \leq \rho \leq 1
\end{array}\right\}, \\
\frac{\partial \mathrm{T}}{\partial \rho}+\mathrm{mT}=0, \cdot\left\{\begin{array}{l}
\rho=1 \\
-\infty<\zeta<\infty
\end{array}\right\}, &
\end{array}
$$

where $m=h a / k$ is the Biot number and

$$
f_{1}(\zeta)= \begin{cases}1, & 0 \leq|\zeta| \leq \beta ; \\ \frac{1}{\epsilon}(\beta+\epsilon-|\zeta|), & \beta \leq|\zeta| \leq \beta+\epsilon \\ 0, & \beta+\epsilon \leq|\zeta|<\infty .\end{cases}
$$

Denoting the Fourier cosine transform of a function, $f_{1}(\zeta)$. say, by $\tilde{\mathrm{f}}_{1}(\mathrm{p})$, we obtain as the transformed problem

$$
\left.\begin{array}{c}
\nabla_{1}^{2} \tilde{\mathrm{T}}-\mathrm{p}^{2} \tilde{\mathrm{T}}=\tilde{\mathrm{f}}_{1}(\mathrm{p}) \mathrm{I}_{0}(\kappa \rho), \\
\vdots \tilde{\mathrm{T}}+\mathrm{m} \tilde{\mathrm{T}}=0, \quad \rho=1,
\end{array}\right\}
$$

where

$$
\nabla_{1}^{2} \equiv \frac{\partial^{2}}{\partial \rho^{2}}+\frac{1}{\rho} \frac{\partial}{\partial \rho}
$$

and

$$
\tilde{f}_{1}(p)=\left(\frac{2}{\pi}\right)^{1 / 2} \frac{1}{\epsilon p^{2}}[\cos p \beta-\cos (\beta+\epsilon) p]
$$

Equations (3) immediately yield

$$
\dot{\tilde{\mathrm{T}}}=\mathrm{A}(\mathrm{p}) \dot{\mathrm{I}}_{0}(\mathrm{p} \rho)+\mathrm{B}(\mathrm{p}) \mathrm{I}_{0}(\kappa \rho)
$$

where

$$
B(p)=\tilde{f}_{1}(p)\left(\kappa^{2}-p^{2}\right)^{-1},
$$

and

$$
A(p)=-B(p)\left[\frac{\kappa I_{1}(\kappa)+m I_{0}(\kappa)}{p I_{1}(p)+m I_{0}(p)}\right]
$$


Thus, upon inversion, we have as the temperature field

$\mathrm{T}(\rho, \zeta)=\frac{2}{\pi} \int_{0}^{\infty} \frac{[\cos \beta \mathrm{p}-\cos (\beta+\epsilon) \mathrm{p}] \cos \mathrm{p} \zeta\left\{\mathrm{I}_{0}(\kappa \rho)\left[\mathrm{pI}_{1}(\mathrm{p})+\mathrm{mI}_{0}(\mathrm{p})\right]-\mathrm{I}_{0}(\mathrm{p} \rho)\left[\kappa \mathrm{I}_{1}(\kappa)+\mathrm{mI}_{0}(\kappa)\right]\right\}}{\epsilon \mathrm{p}^{2}\left(\kappa^{2}-\mathrm{p}^{2}\right)\left[\mathrm{pI}_{1}(\mathrm{p})+\mathrm{mI}_{0}(\mathrm{p})\right]} \mathrm{dp}$.

It may easily be verified that this expression is a well-defined solution in that no singularities occur as $\mathrm{p} \rightarrow 0$ or $\mathrm{p} \rightarrow \kappa$, and that as $\mathrm{p} \rightarrow \infty$ the integrand decays in the proper manner. As mentioned in Section $I$, however. we will only be treating the case of no radial dependence in the heat generation and thus are interested only in the limiting case $\kappa \rightarrow 0$. This yields

$T(\rho, \zeta)=-\frac{2}{\pi} \int_{0}^{\infty} \frac{[\cos \beta p-\cos (\beta+\epsilon) p] \cos p \zeta\left\{p I_{1}(p)+m\left[I_{0}(p)-I_{0}(p \rho)\right]\right\}}{\epsilon p^{4}\left[p I_{1}(p)+m I_{0}(p)\right]} d p$.

We note one other special case of the above result. When $\epsilon \rightarrow 0$ (i.e., when the axial heat-generation rate has a jump at $\zeta=\beta$ rather than a ramp decrease), the temperature integral reduces to

$$
T(\rho, \zeta)=-\frac{2}{\pi} \int_{0}^{\infty} \frac{\sin \beta p \cos p \zeta\left\{p I_{1}(p)+m\left[I_{0}(p)-I_{0}(p p)\right]\right\}}{p^{3}\left[p I_{1}(p)+m I_{0}(p)\right]} d p
$$

We shall solve the thermal-stress problem using the temperature field given by Eq. (4). To recover the solution for the case of nonzero $\epsilon$, we only have to replace the term $\mathrm{p}^{-1} \sin \beta \mathrm{p}$ occurring in each of the stress integrals with $\left[\epsilon \mathrm{p}^{2}\right]^{-1}[\cos \beta \mathrm{p}-\cos (\beta+\epsilon) \mathrm{p}]$, there being neither $\rho$ nor $\zeta$ dependence in either term and hence no alteration of these terms in any of the manipulations to follow.

\section{THE STRESS FIELD}

The problem as stated in Section I is one of torsionless axisymmetry; hence a multitude of practical methods are available for the determination of the stress field. We choose to treat the problem in terms of a relatively unfamiliar set of stress functions devised by Hoyle. ${ }^{2}$ In its technical details, this solution is quite similar to one in terms of the Love function and was chosen because of an interest in eventually comparing the present isotropic case with that for transverse isotropy. Such a comparison can be conveniently handled in terms of the Hoyle functions since their exact analog in the transversely isotropic case has been extensively developed by Singh. ${ }^{3}$ It should be mentioned that the results of the present section were checked by an alternate solution of the problem using a Papkovich-Neuber stress-function formulation (see Nowacki, ${ }^{4}$ pp. 243-253). 
The algebraic detail involved in the Papkovich-Neuber. solution was somewhat more cumbersome than that of the Hoyle treatment, and hence the latter is being presented.

Omitting the details of the derivation given by Hoyle, we note that the stress functions $\hat{\Omega}$ and $\hat{\Phi}$ satisfy the equations

$$
\left.\begin{array}{l}
\frac{\partial^{2} \hat{\Omega}}{\partial \mathrm{r}^{2}}+\frac{1}{\mathrm{r}} \frac{\partial \hat{\Omega}}{\partial \mathrm{r}}+\frac{\partial^{2} \hat{\Omega}}{\partial z^{2}}=0 \\
\frac{\partial^{2} \hat{\Phi}}{\partial \mathrm{r}^{2}}+\frac{1}{\mathrm{r}} \frac{\partial \hat{\Phi}}{\partial \mathrm{r}}+\frac{\partial^{2} \hat{\Phi}}{\partial \mathrm{z}^{2}}=\frac{1}{1-\nu}\left(\frac{\partial^{2} \hat{\Omega}}{\partial \mathrm{z}^{2}}-\alpha E \hat{\mathrm{T}}_{1}\right)
\end{array}\right\}
$$

and are related to the displacements and stresses by

$$
\begin{gathered}
\hat{u}=-\frac{1+\nu}{E}\left(\frac{\partial \hat{\Phi}}{\partial r}+\frac{\partial \hat{\Omega}}{\partial r}\right), \\
\hat{w}=-\frac{1+\nu}{E}\left(\frac{\partial \hat{\Phi}}{\partial z}-\frac{\partial \hat{\Omega}}{\partial z}\right), \\
\hat{\sigma}_{r r}=\frac{\partial^{2} \hat{\Phi}}{\partial z^{2}}+\frac{1}{r}\left(\frac{\partial \hat{\Phi}}{\partial r}+\frac{\partial \hat{\Omega}}{\partial r}\right), \\
\hat{\sigma}_{\theta \theta}=\nu \nabla^{2} \hat{\Phi}-\frac{1}{r}\left(\frac{\partial \hat{\Phi}}{\partial r}+\frac{\partial \hat{\Omega}}{\partial r}\right)-\alpha E \hat{T}_{1}, \\
\hat{\sigma}_{z z}=\nabla_{1}^{2} \hat{\Phi}, \quad \hat{\sigma}_{r z}=-\frac{\partial^{2} \hat{\Phi}}{\partial r \partial z} .
\end{gathered}
$$

The temperature denoted by $\hat{\mathrm{T}}_{1}$ is the temperature above some stress-free initial temperature. We shall assume the rod is stress free at $T_{0}$, the temperature of the surrounding medium. Thus, in the notation of Section II,

$$
\hat{\mathrm{T}}_{1} \equiv \hat{\mathrm{T}}-\mathrm{T}_{0}=-\mathrm{Q}_{1} \mathrm{~T}_{0} \mathrm{~T} \text {. }
$$

If we introduce dimensionless quantities as before and the additional relations

$$
\begin{aligned}
& \hat{\Phi}=\frac{a^{2} E \alpha T_{0} Q_{1}}{1-\nu} \Phi, \quad \hat{T}_{1}=Q_{1} T_{0} T_{1}, \\
& \hat{\Omega}=\frac{a^{2} E \alpha T_{0} Q_{1}}{1-\nu} \Omega,
\end{aligned}
$$




$$
\begin{aligned}
& \hat{\sigma}_{i j}=\frac{E \alpha T_{0} Q_{1}}{1-\nu} \sigma_{i j}, \\
& \hat{u}=\frac{1+\nu}{1-\nu} a \alpha T_{0} Q_{1} u,
\end{aligned}
$$

and

$$
\hat{\mathrm{w}}=\frac{1+\nu}{1-\nu} \mathrm{aax}_{0} \mathrm{Q}_{1} \mathrm{w}
$$

Eqs. (5) and (6) become

$$
\left.\begin{array}{l}
\nabla^{2} \Omega=0, \\
\nabla^{2} \Phi=\frac{1}{1-\nu} \frac{\partial^{2} \Omega}{\partial \zeta^{2}}-\mathrm{T}_{1} ;
\end{array}\right\}
$$

and

$$
\left.\begin{array}{l}
\sigma_{\rho \rho}=\frac{\partial^{2} \Phi}{\partial \zeta^{2}}+\frac{1}{\rho}\left(\frac{\partial \Phi}{\partial \rho}+\frac{\partial \Omega}{\partial \rho}\right), \\
\sigma_{\phi \phi}=\nu \nabla^{2} \Phi-\frac{1}{\rho}\left(\frac{\partial \Phi}{\partial \rho}+\frac{\partial \Omega}{\partial \rho}\right)-(1-\nu) \mathrm{T}_{1}, \\
\sigma_{\zeta \zeta}=\nabla_{1}^{2} \Phi, \quad \sigma_{\rho \zeta}=-\frac{\partial^{2} \Phi}{\partial \rho \partial \zeta} .
\end{array}\right\}
$$

The boundary conditions of zero surface tractions,

$$
\sigma_{\rho \zeta}=\sigma_{\rho \rho}=0, \quad \rho=1, \quad-\infty<\zeta<\infty,
$$

imply

$$
\left.\begin{array}{l}
{\left[\frac{\partial^{2} \Phi}{\partial \zeta^{2}}+\frac{1}{\rho}\left(\frac{\partial \Phi}{\partial \rho}+\frac{\partial \Omega}{\partial \rho}\right)\right]_{\rho=1}=0} \\
{\left[-\frac{\partial^{2} \Phi}{\partial \rho \partial \zeta}\right]_{\rho=1}=0}
\end{array}\right\}
$$


Thus, the problem requires the solution of Eqs. (7) with the boundary conditions (10), the temperature field being given by

$$
\therefore \mathrm{T}_{1}=\frac{2}{\pi} \int_{0}^{\infty} \frac{\sin \beta \mathrm{p} \cos \mathrm{p} \zeta\left\{\mathrm{pI} \mathrm{I}_{1}(\mathrm{p})+\mathrm{m}\left[\mathrm{I}_{0}(\mathrm{p})-\mathrm{I}_{0}(\mathrm{p} \rho]\right\}\right.}{\mathrm{p}^{3}\left[\mathrm{pI} \mathrm{I}_{1}(\mathrm{p})+\mathrm{mI}_{0}(\mathrm{p})\right]} \mathrm{dp}
$$

We proceed with the solution in a formal manner, the validity of the various integral expressions being verified a posteriori. The solution of the first of (7) is taken in the form

$$
\Omega=\frac{2}{\pi} \int_{0}^{\infty} \sin \beta p \cos p \zeta I_{0}(p \rho) A(p) d p
$$

where $A(p)$ is an as yet undefined function of $p$ and independent of $\rho$ and $\zeta$. The solution of the second of (7) is taken as

$$
\Phi=\Phi_{0}+\Phi_{1}+\Phi_{2}
$$

where

$$
\begin{aligned}
& \nabla^{2} \Phi_{0}=0 \\
& \nabla^{2} \Phi_{1}=\frac{1}{1-\nu} \frac{\partial^{2} \Omega}{\partial \zeta^{2}}
\end{aligned}
$$

and

$$
\nabla^{2} \Phi_{2}=-\mathrm{T}_{1}
$$

In a manner analogous with (12), we have

$$
\Phi_{0}=\frac{2}{\pi} \int_{0}^{\infty} \sin \beta \mathrm{p} \cos \mathrm{p} \zeta \mathrm{I}_{0}(\mathrm{p} \rho) \mathrm{B}(\mathrm{p}) \mathrm{d} \dot{\mathrm{p}}
$$

where $B(p)$ is as yet arbitrary. For the particular solutions $\Phi_{1}$, $\Phi_{2}$, we obtain

$$
\Phi_{1}=-\left(\frac{2}{\pi}\right) \frac{1}{2(1-\nu)} \int_{0}^{\infty} \sin \beta p \cos p \zeta\left[p \rho I_{1}(p \rho)\right] A(p) d p
$$


and

$$
\begin{aligned}
& \Phi_{2}=\frac{2}{\pi} \int_{0}^{\infty} \frac{\sin \beta p \cos p \zeta}{2 p^{5}\left[p I_{1}(p)+m I_{0}(p)\right]}\left\{m p \rho I_{1}(p \rho)+2\left[p I_{1}(p)+m I_{0}(p)\right]\right. \\
& \left.-\left[2 m+p^{2}\left(1+\frac{m}{2}\right)\right] I_{0}(p \rho)\right\} d p \text {. }
\end{aligned}
$$

These integrals can be easily obtained by standard Fourier transform methods. However, this process, when applied to the derivation of the integral for $\Phi_{2}$, results in an improper integral in.that the integrand is singular at the lower limit, the singularity being independent of $\rho$ and $\zeta$. The last term in brackets of the integral for $\Phi_{2}$ results from subtracting from the transform result an appropriate harmonic function chosen in such a manner as to remove this singularity.

By combining the above results and applying the boundary conditions (10), we obtain as the equations defining the functions $A(p)$ and $B(p)$

$$
A_{1}(p)\left[p I_{0}(p)\right]-B_{1}(p)\left[I_{1}(p)\right]=m p I_{0}(p)-\left[2 m+p^{2}\left(1+\frac{m}{2}\right)\right] I_{1}(p)
$$

and

$$
A_{1}(p)\left[2(1-\nu)+p^{2}\right]-B_{1}(p)\left[p I_{0}(p)\right]=p^{2}\left(1+\frac{m}{2}\right)\left[2 I_{1}(p)-p I_{0}(p)\right]
$$

where

$$
A(p)=\frac{1-\nu}{p^{5}\left[p I_{1}(p)+m I_{0}(p)\right]} A_{1}(p)
$$

and

$$
\left.B(p)=\frac{1}{2 p^{5}\left[p I_{1}(p)+m I_{0}(p)\right]} B_{1}(p) .\right\}
$$

Solving the system (13) yields

$$
A_{1}(p)=\frac{p}{\Delta(p)}\left\{-m p I_{0}^{2}(p)+2 m I_{0}(p) I_{1}(p)+2\left(1+\frac{m}{2}\right) \mathrm{pI}_{1}^{2}(p)\right\}
$$

and

$$
\begin{aligned}
\mathrm{B}_{1}(\mathrm{p})= & \frac{1}{\Delta(\mathrm{p})}\left\{-\left(1+\frac{\mathrm{m}}{2}\right) \mathrm{p}^{4} \mathrm{I}_{0}^{2}(\mathrm{p})-2 \mathrm{pI}(\mathrm{p}) \mathrm{I}_{1}(\mathrm{p})\left[\mathrm{m}(1-\nu)-\mathrm{p}^{2}\right]\right. \\
& \left.+\left[2(1-\nu)+\mathrm{p}^{2}\right]\left[2 \mathrm{~m}+\mathrm{p}^{2}\left(1+\frac{\mathrm{m}}{2}\right)\right] \mathrm{I}_{1}^{2}(\mathrm{p})\right\}
\end{aligned}
$$


where

$$
\Delta(p)=\left[2(1-\nu)+p^{2}\right] I_{1}^{2}(p)-p^{2} I_{0}^{2}(p)
$$

a function. characteristic of such problems in cylindrical coordinates. Upon combining the above results, we obtain as the required stress functions

$$
\begin{aligned}
\Omega= & \frac{2(1-\nu)}{\pi} \int_{0}^{\infty} \frac{\sin \beta p \cos p \zeta}{p^{4} \Delta(p)\left[p I_{1}(p)+m I_{0}(p)\right]}\left[-m p I_{0}^{2}(p)\right. \\
& \left.+2 m I_{0}(p) I_{1}(p)+2\left(1+\frac{m}{2}\right) \mathrm{pI}_{1}^{2}(p)\right] I_{0}(p \rho) d p
\end{aligned}
$$

and

$$
\begin{aligned}
\Phi= & \frac{2}{\pi} \int_{0}^{\infty} \frac{\sin \beta p \cos p \zeta}{p^{5} \Delta(p)\left[p I_{1}(p)+\mathrm{mI}_{0}(p)\right]}\left\{\left(\left[m(1-\nu)-\mathrm{p}^{2}\right] \mathrm{I}_{1}(\mathrm{p})-\mathrm{mpI}_{0}(\mathrm{p})\right)\right. \\
& \left.\cdot\left(\mathrm{p} \rho \mathrm{I}_{1}(\mathrm{p}) \mathrm{I}_{1}(\mathrm{p} \rho)-\mathrm{pI}_{0}(\mathrm{p}) \mathrm{I}_{0}(\mathrm{p} \rho)\right)+\Delta(\mathrm{p})\left[\mathrm{pI}_{1}(\mathrm{p})+\mathrm{mI}_{0}(\mathrm{p})\right]\right\} \mathrm{dp} .
\end{aligned}
$$

Examining the behavior of (17) and (18) in the limit of $p \rightarrow 0$, we find that these functions are singular; however, the singularity is again independent of the variables $\rho$ and $\zeta$ and may be easily removed. This is merely a reflection of the fact that the stress functions are arbitrary to within a constant since only derivatives of these functions are required in determining the stresses and displacements. We choose not to incorporate the additional terms since they make no contribution to the final results.

Substitution of (17) and (18) into (9) yields, after simplification,

$$
\begin{aligned}
\sigma_{\rho \rho}= & \frac{2}{\pi} \int_{0}^{\infty} \frac{\sin \beta p \cos p \zeta}{p^{3} \Delta(p)\left[p I_{1}(p)+m I_{0}(p)\right]}\left\{\left[m(1-\nu)-p^{2}\right] I_{1}(p)-m p I_{0}(p)\right\} \\
& :\left\{I_{0}(p \dot{p})\left[p I_{0}(p)+I_{1}(p)\right]-p \dot{p} I_{1}^{\prime}(p) I_{1}(p \dot{\rho})\right\} \\
& +\rho^{-1} I_{1}(p \rho)\left\{m \nu p I_{0}^{2}(p)+\left[m(1-\nu)+p^{2}\right] I_{0}(p) I_{1}(p)\right. \\
& \left.\left.+2(1-\nu)\left(1+\frac{m}{2}\right) p I_{1}^{2}(p)\right\}-\Delta(p)\left[p I_{1}(p)+m I_{0}(p)\right]\right\} d p
\end{aligned}
$$




$$
\begin{aligned}
\sigma_{\phi \phi}= & \frac{2}{\pi} \int_{0}^{\infty} \frac{\sin \beta p \cos p \zeta}{p^{3} \Delta(p)\left[p I_{1}(p)+m I_{0}(p)\right]}\left\{I _ { 0 } ( p \rho ) \left[\left\{m(1-\nu)+p^{2}[(1-2 \nu)+m(1-\nu)]\right\}\right.\right. \\
& \left.I_{1}^{2}(p)+m(1-2 \nu) p I_{0}(p) I_{1}(p)-m(1-\nu) p^{2} I_{0}^{2}(p)\right]-\rho^{-1} I_{1}(p \rho)\left\{m \nu p I_{0}^{2}(p)\right. \\
& \left.+\left[m(1-\nu)+p^{2}\right] I_{0}(p) I_{1}(p)+2(1-\nu)\left(1+\frac{m}{2}\right) p I_{1}^{2}(p)\right\} \\
& \left.-\Delta(p)\left\lfloor p I_{1}(p)+m I_{0}(p)\right]\right\} d p \\
\sigma_{\zeta \zeta}= & \frac{2}{\pi} \int_{0}^{\infty} \frac{\sin \beta p \cos p \zeta}{p^{3} \Delta(p)\left[p I_{1}(p)+m I_{0}(p)\right]}\left\{\left[m(1-\nu)-p^{2}\right] I_{1}(p)-m p I_{0}(p)\right\} \\
& .\left\{\left[2 I_{1}(p)-p I_{0}(p)\right] I_{0}(p \rho)-p \rho I_{1}(p) I_{1}(p \rho)\right\} d p
\end{aligned}
$$

and

$$
\begin{aligned}
\sigma_{\rho \zeta}= & \frac{2}{\pi} \int_{0}^{\infty} \frac{\sin \beta p \sin p \zeta}{p^{2} \Delta(p)\left[p I_{1}(p)+m I_{0}(p)\right]}\left\{\left[m(1-\nu)-p^{2}\right] I_{1}(p)-m p I_{0}(p)\right\} \\
& \cdot\left[\rho I_{0}(p \rho) I_{1}(p)-I_{0}(p) I_{1}(p \rho)\right] d p
\end{aligned}
$$

For the displacements, Eqs. (8) yield

$$
\begin{aligned}
& u=-\frac{2}{\pi} \int_{0}^{\infty} \frac{\sin p \beta \cos p \zeta}{p^{3} \Delta(p)\left[p I_{1}(p)+m I_{0}(p)\right]}\left\{I_{1}(p)\left[\left[m(1-\nu)-p^{2}\right] I_{1}(p)-m p I_{0}(p)\right]\right. \\
& \rho I_{0}(p \rho)+\left[\left[m(1-\nu)+p^{2}\right] I_{0}(p) I_{1}(p)+\nu m p I_{0}^{2}(p)+2(1-\nu)\right. \\
& \left.\left.\left(1+\frac{m}{2}\right) p I_{1}^{2}(p)\right] I_{1}(p \rho)\right\} d p,
\end{aligned}
$$

and

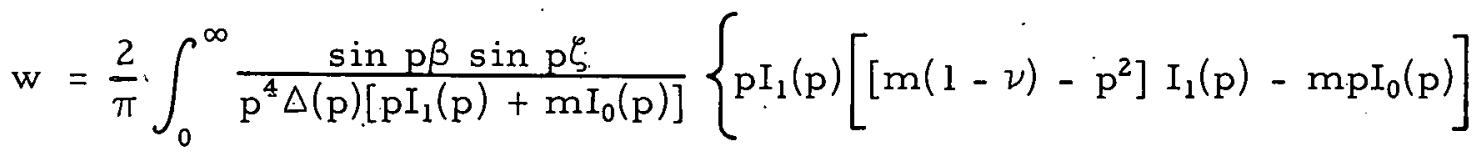

$$
\begin{aligned}
& \rho I_{1}(p \rho)+p I_{0}(p \rho)\left[m(2-\nu) p I_{0}^{2}(p)-\left[3 m(l-\nu)-p^{2}\right] I_{0}(p) I_{1}(p)-2(1-\nu)\right. \\
& \left.\left.\left(1+\frac{m}{2}\right) \dot{p I} I_{1}^{2}(p)\right]+\Delta(p)\left[p I_{1}(p)+m I_{0}(p)\right]\right\} d p
\end{aligned}
$$




\section{NUMERICAL RESULTS AND DISCUSSION}

Because of the large number of parameters in the problem, it did not seem feasible to provide plots of the temperature and stress field for extensive ranges and combinations of their possible values. Rather, we shall indicate the general behavior of the solution by several sample results. The temperature integral (11) and the stress integrals (19)-(21) are sufficiently well behaved that their numerical evaluation provides no outstanding problems, and results needed for any specific application can be readily computed. The decay of all the integrands with large values of the integration variable is extremely rapid, and it has not proven necessary in the computations to perform an exact evaluation of the contribution of the asymptotic "tails" in order to achieve results of an accuracy sufficient for practical applications. For example, in dealing with a large value of $\beta$, say $\beta=4.0$, we computed stresses by truncating the integration at $p=16.0$, using a step length of $\Delta \mathrm{p}=0.2$, and evaluating by a modified Simpson's rule. By examining the decay of the stresses for large values of $\zeta$ and noting when an oscillatory pattern begins to develop, we find that this crude process of evaluation yields four-place accuracy in the range of $\zeta$ of interest (i.e., in the neighborhood of $\zeta=\beta$ ).

The nature of the stress field is best illustrated by. considering the stresses as functions of $\zeta$ for specific values of $\rho$. The stress integrals have been evaluated along the center of the rod $(\rho=0.0)$ and at the rod surface $(\rho=1.0)$. For these specific values, the integrals (19)-(22) have the following form:

$\rho=0$

$$
\begin{aligned}
& \sigma_{\zeta \rho}(0, \zeta) \equiv 0 \\
& \sigma_{\rho \rho}(0, \zeta)=\sigma_{\phi \phi}(0, \zeta)=\frac{2}{\pi} \int_{0}^{\infty} \frac{\sin \beta p \cos p \zeta}{\mathrm{p}^{3} \Delta(\mathrm{p})\left[\mathrm{pI} \mathrm{I}_{1}(\mathrm{p})+\mathrm{mI_{0 }}(\mathrm{p})\right]} \cdot\left\{-\frac{\mathrm{m}}{2}(2-\nu) \mathrm{p}^{2} \mathrm{I}_{0}^{2}(\mathrm{p})\right. \\
&++\mathrm{pI}_{0}(\mathrm{p}) \mathrm{I}_{1}(\mathrm{p})\left[\frac{\mathrm{m}}{2}(1-\nu)-\mathrm{m} \nu-\frac{\mathrm{p}^{2}}{2}\right]+\mathrm{I}_{1}^{2}(\mathrm{p})[\mathrm{m}(1-\nu) \\
&\left.\left.+\mathrm{p}^{2}\left(-\nu+\frac{\mathrm{m}}{2}(1-\nu)\right)\right]-\Delta(\mathrm{p})\left[\mathrm{pI}_{1}(\mathrm{p})+\mathrm{mI}_{0}(\mathrm{p})\right]\right\} \mathrm{dp}
\end{aligned}
$$

and

$$
\begin{aligned}
\sigma_{\zeta \zeta}(0, \zeta)= & -\frac{2}{\pi} \int_{0}^{\infty} \frac{\sin \beta p \cos p \zeta}{p^{3} \Delta(p)\left[p I_{1}(p)+m I_{0}(p)\right]}\left\{-m^{2} I_{0}^{2}(p)+\left[m(1-\nu)+2 m-p^{2}\right]\right. \\
& \left.p I_{0}(p) I_{1}(p)-2\left[m(1-\nu)-p^{2}\right] I_{1}^{2}(p)\right\} d p .
\end{aligned}
$$


$\underline{p}=1.0$

$$
\begin{gathered}
\sigma_{\zeta \rho}(1, \zeta)=\sigma_{\rho \rho}(1, \zeta) \equiv 0, \\
\sigma_{\phi \phi}(1, \zeta)=\frac{2}{\pi} \int_{0}^{\infty} \frac{\sin \beta p \cos p \zeta}{\mathrm{p}^{3} \Delta(\mathrm{p})\left[\mathrm{pI}(\mathrm{p})+\mathrm{mI}_{0}(\mathrm{p})\right]}\left\{\mathrm{pI}_{0}^{2}(\mathrm{p}) \mathrm{I}_{1}(\mathrm{p})\left[\mathrm{m}(\mathrm{l}-3 \nu)+\mathrm{p}^{2}\right]\right. \\
\quad-\mathrm{I}_{0}(\mathrm{p}) \mathrm{I}_{1}^{2}(\mathrm{p})\left[2 \mathrm{~m}(1-\nu)+\mathrm{p}^{2}(\mathrm{~m}+2) \nu\right]-\mathrm{pI}_{1}^{3}(\mathrm{p})\left[(\mathrm{m}+4)(1-\nu)+\mathrm{p}^{2}\right) \\
\left.+\nu \mathrm{mp}^{2} \mathrm{I}_{0}^{3}(\mathrm{p})\right\} \mathrm{dp}, \\
\quad \sigma_{\zeta \zeta}(1, \zeta)=-\frac{2}{\pi} \int_{0}^{\infty} \frac{\mathrm{sin} \beta \mathrm{p} \cos \mathrm{p} \zeta}{\mathrm{p}^{3} \Delta(\mathrm{p})\left[\mathrm{pI} \mathrm{I}_{\mathrm{l}}(\mathrm{p})+\mathrm{mI}_{0}(\mathrm{p})\right]}\left\{\mathrm{pI}_{0}^{2}(\mathrm{p}) \mathrm{I}_{1}(\mathrm{p})\left[\mathrm{m}(3-\nu)-\mathrm{p}^{2}\right]\right. \\
\quad-\mathrm{I}_{0}(\mathrm{p}) \mathrm{I}_{1}^{2}(\mathrm{p})\left[2 \mathrm{~m}(1-\nu)-\mathrm{p}^{2}(\mathrm{~m}+2)\right]-\mathrm{pI}_{1}^{3}(\mathrm{p})\left[\mathrm{m}(1-\nu)-\mathrm{p}^{2}\right] \\
\left.\quad-\mathrm{mp}^{2} \mathrm{I}_{0}^{3}(\mathrm{p})\right\} \mathrm{dp},
\end{gathered}
$$

and

$$
\begin{aligned}
u(1, \zeta)= & \frac{2(1-\nu)}{\pi} \int_{0}^{\infty} \frac{\sin p \beta \cos p \zeta}{p^{3} \Delta(p)\left[p I_{1}(p)+m I_{0}(p)\right]}\left[m p I_{0}^{2}(p)-2 m I_{0}(p) I_{1}(p)\right. \\
& \left.-2\left(1+\frac{m}{2}\right) \mathrm{pI}_{1}^{2}(p)\right] I_{1}(p) d p .
\end{aligned}
$$

Figures 2 through 10 relate to a value of $\beta=4.0, \epsilon=0.0$, and are typical of the results one obtains for "large" values of $\beta$ in that the stress

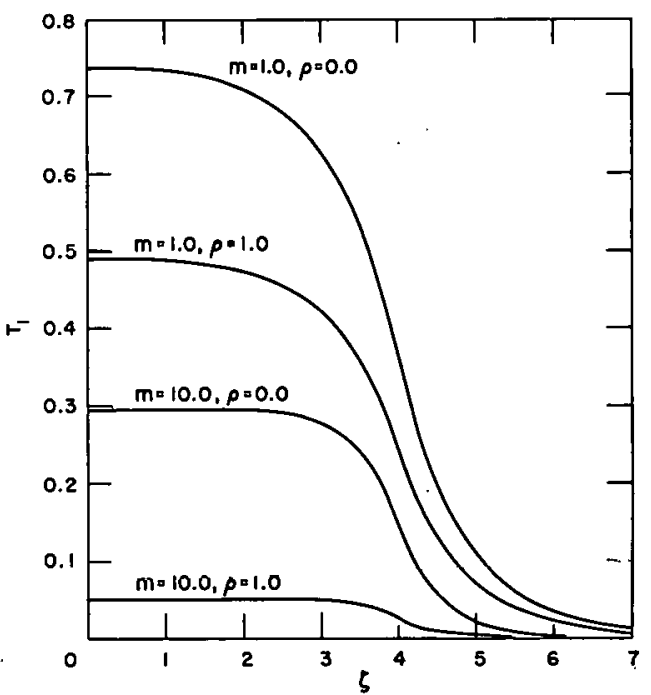

Fig. 2. Axial Temperature Profiles $(\beta=4.0)$

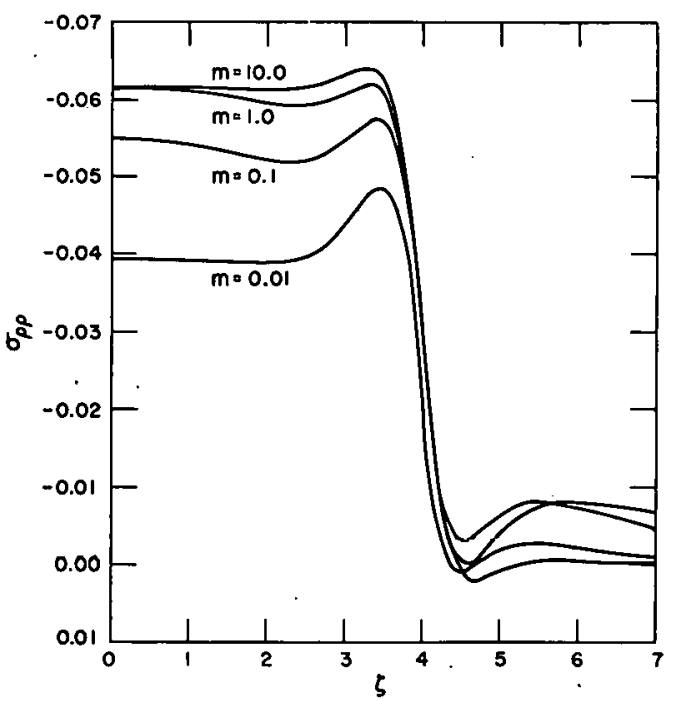

Fig. 3. Radial Stress at Cylinder Centerline $(\beta=4.0, \nu=0.25, \rho=0.0)$ 


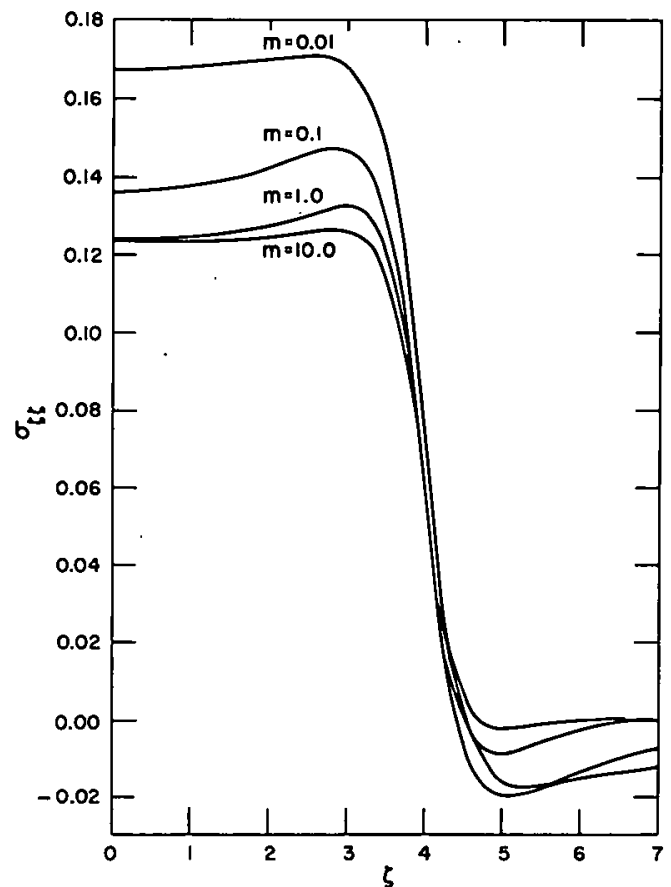

Fig. 4. Axial Stress at Cylinder Surface $(\beta=4.0, \nu=0.25, \rho=1.0)$

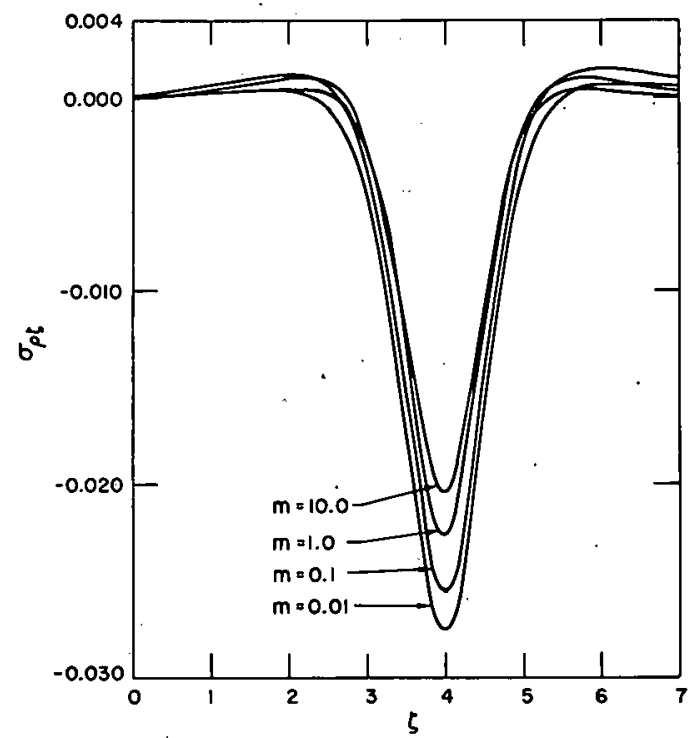

Fig. 6. Shear Stress at $\beta=0.5$ $(\beta=4.0, \nu=0.25)$

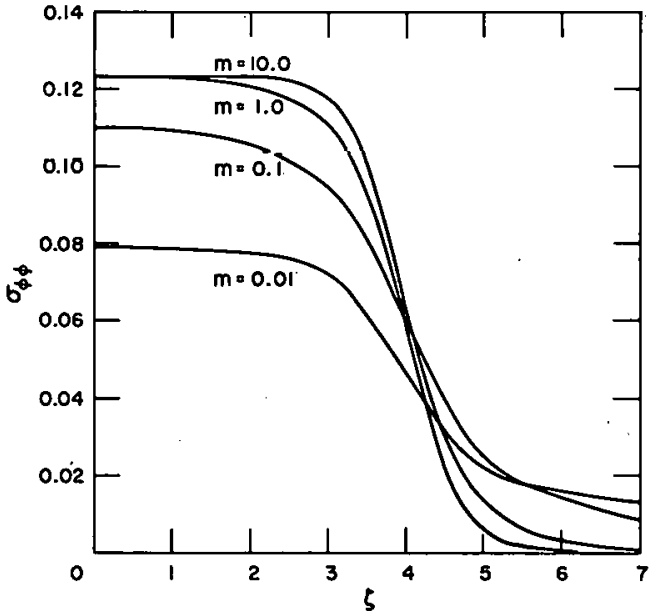

Fig. 5. Circumferential Stress at Cylinder Surface $(\beta=4.0, \nu=0.25, \rho=1)$

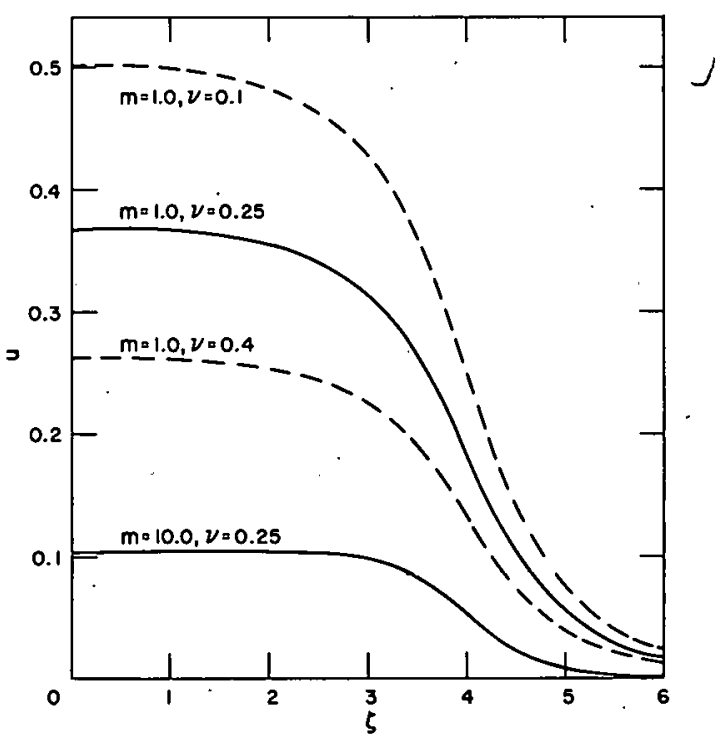

Fig. 7. Radial Displacement of Cylinder Surface $(\beta=4.0)$ 


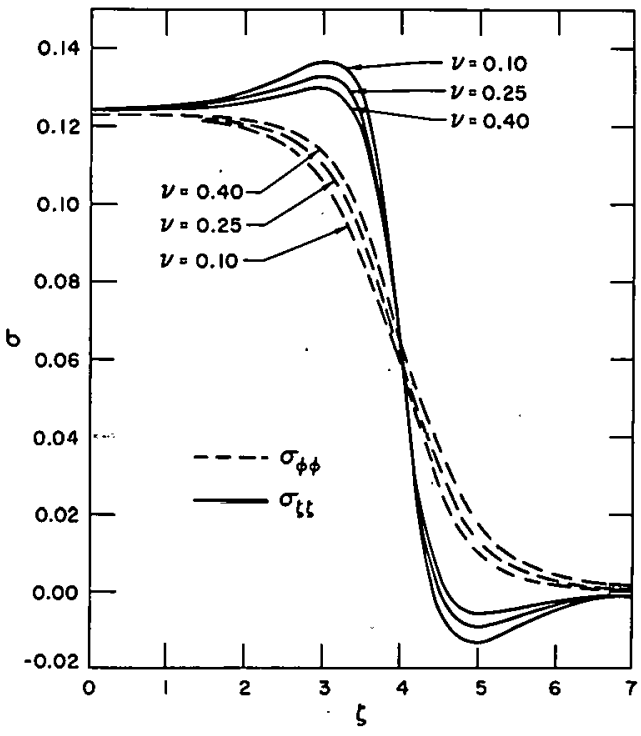

Fig. 8. Effect of Poisson's Ratio on Axial and Circumferential Stress at $C y$ linder Surface $(m=1.0, \beta=4.0)$

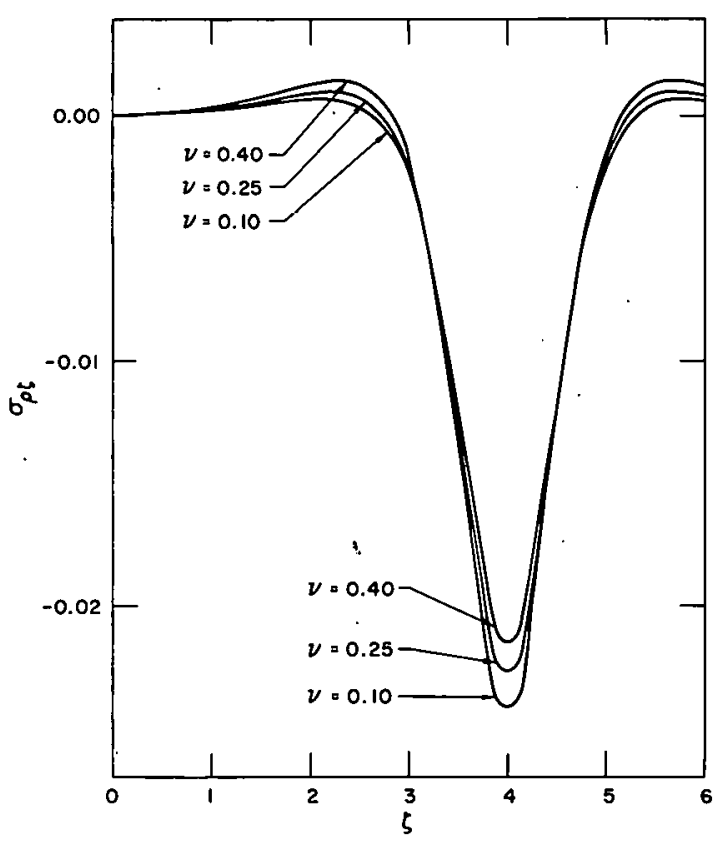

Fig. 10. Effect of Poisson's Ratio on Shear Stress at $\rho=0.5(\beta=4.0, \mathrm{~m}=1.0)$

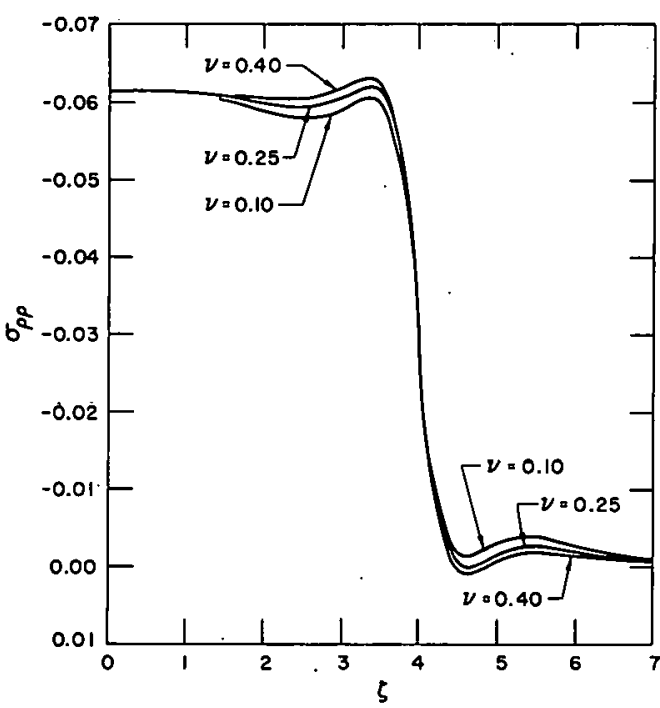

Fig. 9. Effect of Poisson's Ratio on Radial Stress at Cylinder Centerline $(m=1.0, \beta=4.0)$

field near $\zeta=\beta$ is virtually unaffected by the conditions at. $\zeta=-\beta$. In this sense, the solution near $\zeta=\beta$ for $\beta$ large is identical with that near $\zeta=0$ for a heat-generation rate in the form of a Heavyside function (i.e., half the rod generating heat uniformly and the other half with zero generation).

Figure 2 gives representative axial temperature variations at the center and surface of the rod for two values of the Biot number, $m$. As $m$ increases, the effect of axial conduction becomes less important in the neighborhood of $\zeta=0$ and the temperature field flattens in this region, most of the heat being lost radially. As $m$ decreases, the outer surface becomes better insulated, and hence the temperature rises, the flat region

decreases, and axial conduction assumes more importance in determining the shape of the temperature curve. Neglecting all axial effects, the dimensionless temperature field has the form

$$
T=\frac{1}{2}\left[\frac{1}{m}+\frac{1}{2}\left(1-\rho^{2}\right)\right] \text {. }
$$


For large $\mathrm{m}$, large $\beta$, and small $\zeta$, we would expect the temperature field to approach that predicted by (30). That this is. indeed the case can be seen by noting that for $\zeta=0, m=10.0$, and $\beta=4.0$, the temperature integral (11) gives

$$
\mathrm{T}_{1}(0,0) \cong 0.299 .8, \quad \mathrm{~T}_{1}(1.0,0.0) \cong 0.04994,
$$

while (30) yields 0.3 and 0.05 for $\rho=0$ and $\rho=1$, respectively. As either $m$ increases or $\beta$ decreases, Eq. (30) becomes an increasingly poor estimate of the tempcrature, even near $\zeta=0$.

Figure 3 gives the radial stress at the center of the cylinder for various values of the Biot number. Note that as $\mathrm{m}$ decreases, the stress levels decrease but take much longer to decay with increasing $\zeta$. This lat: ter effect is a reflection that in this case the temperature profile still has an appreciable axial gradient for large $\zeta$. For large $m$, there is a sizable region near $\zeta=0$ where the axial temperature profile is flat and hence the stress field approaches

$$
\sigma_{\rho \rho}=-\frac{1}{16}\left(1-\rho^{2}\right)
$$

that is, the radial stress in an infinite cylinder having the temperature field (30). Note that, while the stress $\sigma_{\rho}$ does decrease with decreasing $\mathrm{m}$, the decrease is much slower in the region near $\zeta=\beta$ and thereby produces an appreciable peaking effect.

Figure 4 shows the axial stress at the cylinder surface $\rho=1$. Also, for large $\beta$ it turns out that $\sigma \zeta \zeta$ at $\rho=0$ is approximately the negative of the value for $\rho=1$; hence, with a change of sign the curves of Fig. 4 may be assumed to hold equally well at the cylinder centerline. The axial stress also displays the peaking mentioned in the case of $\sigma \rho \rho$ but to a lesser degree. The behavior of $\sigma_{\zeta \zeta}$ with decreasing $\mathrm{m}$ is reverse of that. for $\sigma \rho p$ in that such a decrease produces an increase in the maximum absolute

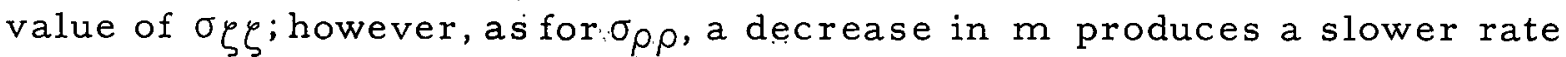
of decay with increasing $\zeta$.

The circumferential (hoop) stress, $\sigma_{\phi \phi}$, at the cylinder surface is given in Fig. 5 and is, in a sense, the most well behaved in that it simply decays monotonically with increasing $\zeta$. For $m$ decreasing, the maximum absolute value of $\sigma_{\phi \phi}$ decreases and the rate of decay in $\zeta$ decreases. For large $m$ and large $\beta$, the stress $\sigma_{\phi \phi}$ near $\zeta=0$ approaches the value one would obtain by neglecting axial conduction and using (30) as the tempera. ture field. That is, the value approaches

$$
\sigma_{\phi \phi}=-\frac{1}{16}\left(1-3 \rho^{2}\right) \text {. }
$$


Figure 6 illustrates the axial behavior of the shear stress, $\sigma_{\rho} \zeta$, and differs from the curves in Figs. 2-5 in that it has been evaluated at $\rho=0.5$ ( $\sigma_{\rho} \zeta$ being zero at both $\rho=0$ and $\rho=1$ ). Note that, while the maximum absolute value of the shear stress is sorrewhat less than that of any of the other stress components, it is a much more localized stress and could for that reason assume major significance in certain applications. Increases in $m$ cause decreases in the maximum absolute value of $\sigma_{\rho} \zeta$, but have little effect on its general form.

The radial displacement of the cylinder surface is shown in Fig. 7. The top three curves illustrate the effect of different values of Poisson's ratio on the expansion and have been calculated for the same value of $\mathrm{m}$ and $\beta$. The two solid curves illustrate the effect of a change in $m$ for constant Poisson's ratio. In its gross behavior, the radial-displacement curve is similar to that of the axial temperature profile, modified by the fact that increases in Poisson's ratio cause sizable decreases in the displacement.

Figures 8 through 10 show the dependence of the various stress components on the value of Poisson's ratio, $\nu$, and all refer to the case $\mathrm{m}=$ 1.0, $\beta=4.0$. Note that changes in $\nu$ have relatively minor effect on all the stresses. At the cylinder surface, an increase in $\nu$ causes decrease in the peak value of $\sigma \zeta \zeta$ and increases the steepness of descent of $\sigma_{\phi \phi}$ near $\zeta=\beta$. At $\rho=0$, an increase in $\nu$ results in a slight increase in $\sigma_{\rho} \rho$, while Fig. 10 shows that increasing $\nu$ decreases the peak value of $\sigma_{\rho \zeta}$.

Figures 11 through 13 are equivalent to Figs. 3 through 5 , respectively, however, with $\beta=1.0$ instead of $\beta=4.0$. Such relatively small

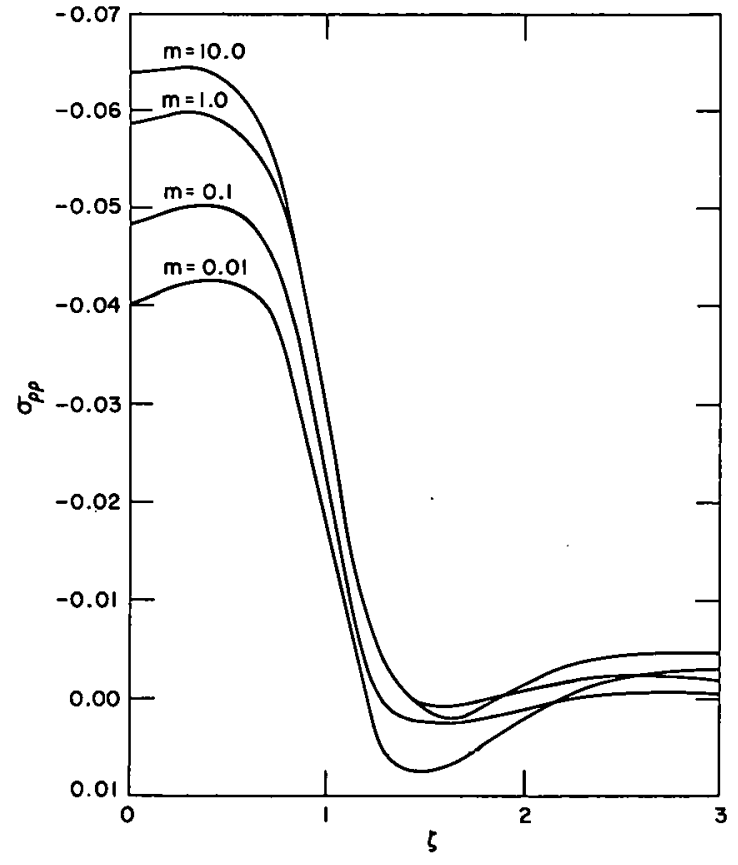

Fig. 11. Radial Stress at Cylinder Centerline $(\beta=1.0, \nu=0.25, \rho=0.0)$ values of $\beta$ have little effect on the rate of decay of the various stress components far from $\zeta=\beta$; however, near $\zeta=0$ the magnitudes and general behavior of the curves are somewhat different. In particular, the various peaking effects (in $\sigma_{\rho \rho}$ and $\sigma \zeta \zeta)$ become less pronounced, and expressions such as (31) and (32) are no longer good approximations for large $\mathrm{m}$. Also, Fig. 12 shows that for small $\beta$ it is no longer true that $\sigma_{\zeta \zeta}(\rho=1.0) \cong-\sigma_{\zeta \zeta}(\rho=0.0)$.

Figures 14 through 17 illus trate the effect of various axial ramp decreases in internal heat generation between the constant generation value at $\zeta=\beta$ and zero generation at $\zeta=$ $\beta+\epsilon$. For example, a value of $\epsilon=$ 1.0 implies that the heat-generation 
rate drops off linearly in $\zeta$ from a value of unity at $\zeta=\beta$ to zero at a distance of one cylinder radius $(\epsilon=1.0)$ from the point $\zeta=\beta$.

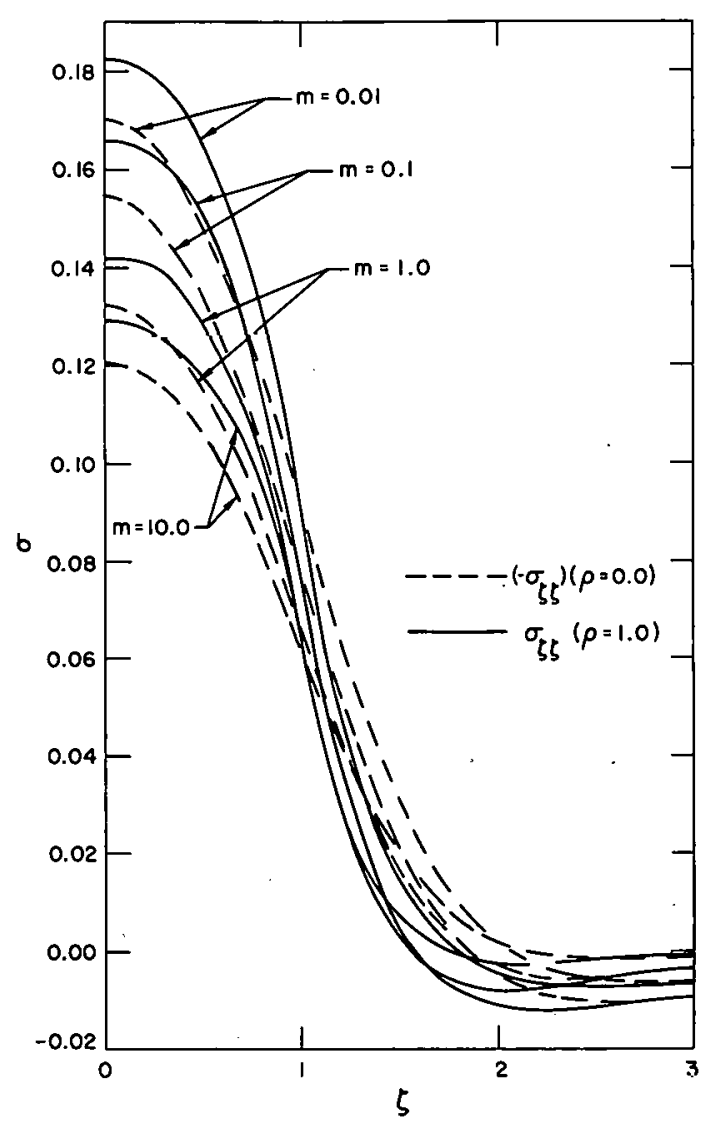

Fig. 12. Axial Stress at Cylinder Surface and Cylinder Centerline $(\beta=1.0, \nu=0.25)$

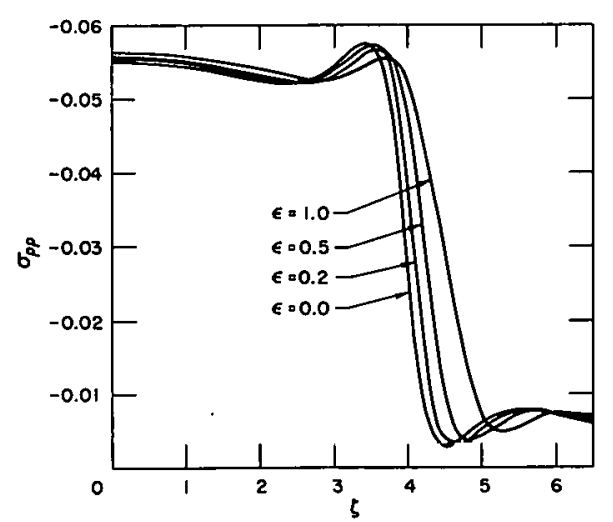

Fig. 14. Effect of Ramp Decrease in Heat Generation on Radial Stress at Cylinder Centerline $(\rho=0.0, \beta=4.0, \nu=0.25, \mathrm{~m}=0.1)$

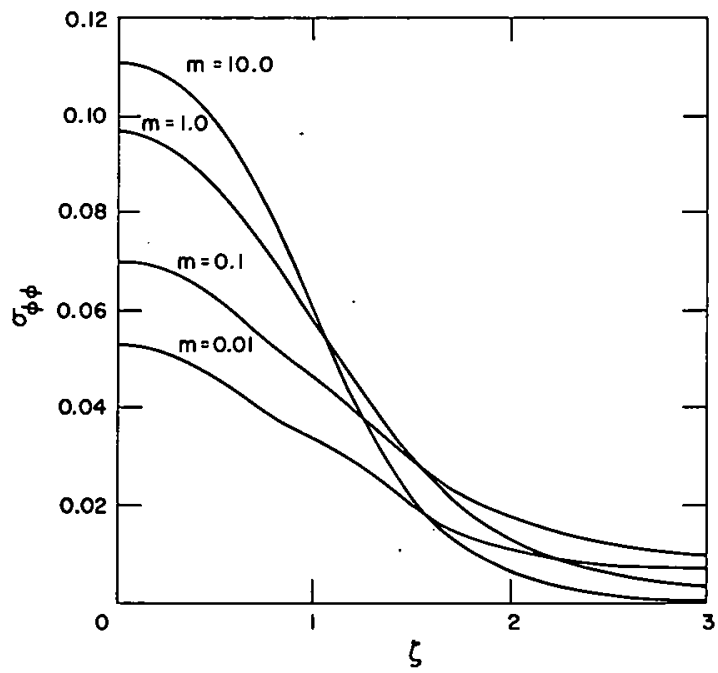

Fig. 13. Circumferential Stress at Cylinder Surface $(\beta=1.0, \nu=0.25, \rho=1)$

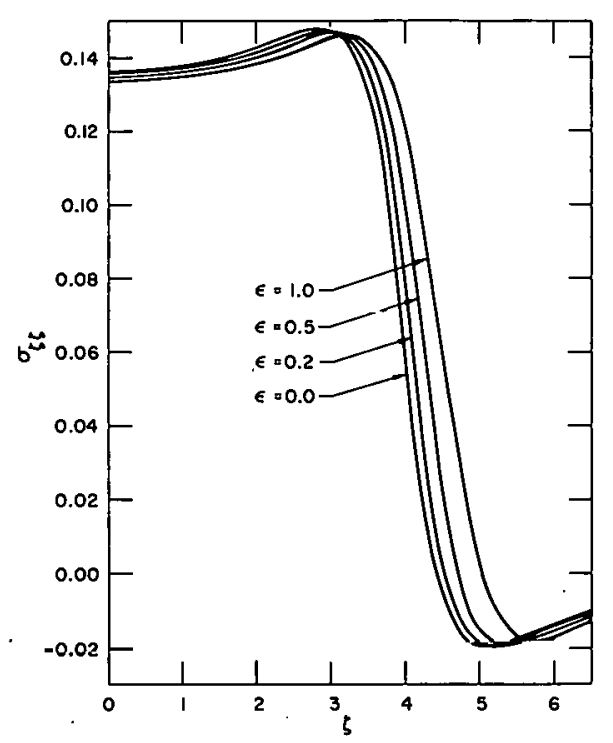

Fig. 15. Effect of Ramp Decrease in Heat Generation on Axial Stress at Cylinder Surface $(\rho=1.0, \beta=4.0, \nu=0.25, m=0.1)$ 


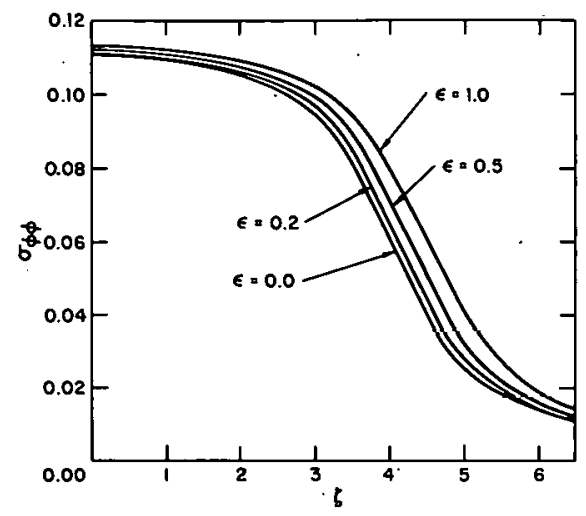

Fig. 16. Effect of Ramp Decrease in Heat Generation on Circum ferential Stress at $C y$ linder Surface $(\rho=1.0, \beta=4.0$, $\nu=0.25, \mathrm{~m}=0.1$ )

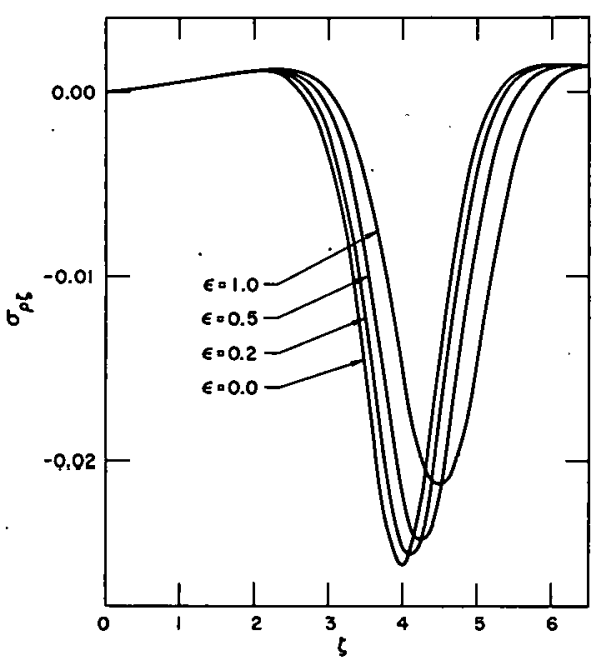

Fig. 17. Effect of Ramp Decrease in Heat Generation on Shear Stress at $\rho=0.5(\beta=4.0$, $\nu=0.25, \mathrm{~m}=0.1$ )

Perhaps the most important observation concerning the results for various values of $\epsilon$ is that the ramp decrease in heat generation as compared with an axial jump is reflected in only minor differences in the stresses. In general, the presence of a ramp tends to produce an axial spread in the stress distribution near $\zeta=\beta$ and a slight reduction in the maximum absolute values of the stresses in this region. The shear stress shown in Fig. 17 is the best illustration of this in that it is the most sensitive to changes in $\epsilon$. Even in this case, however, the decrease in the peak value and the spreading effect are relatively minor.

\section{SUMMARY}

If the length of the uniform heat-generating segment of the fuel pin is long relative to the pin radius, the results. of Section IV indicate that the stress distribution in the generating segment closely approximates that computed on a one-dimensional (radial) basis. The effect of the axial change in heat-generation rate on the stress field is quite localized, as may be most readily seen by noting the small axial range over which the shear stress has an appreciable value. In the region where the shear stress reaches its maximum, the radial and axial stress components are larger than those occurring for uniform generation, and this difference becomes more pronounced as the Biot number decreases; however, even for the smallest Biot number used in the computations $(\mathrm{m}=0.01)$, the increase in stress was less than $20 \%$. Also, in all cases it was observed that large changes in Poisson's ratio produced only minor changes in the stress field. 
The computations relating to changes in the stresses caused by altering the form of the axial heat-generation profile revealed that there are only minor differences between the stress field due to an axial jump and an axial ramp decrease. In general, as the ramp becomes more gradual, axial variations in the stress components become less pronounced and the peak stress values tend to decrease.

\section{REFERENCES}

1. Bonilla, C. F., Nuclear Engineering, McGraw-Hill, New York (1957).

2. Hoyle, R. D., Transient Temperature Stresses in Axially Symmetrical Systems with Special Application to a Solid Rotor of a. Steam Turbine, Proc. Inst. Mech. Engrs. 169 (1955), 553-562.

3. Singh, A., Axisymmetrical Thermal Stresses in Transversely Isotropic Bodies, Arch. Mech. Stos. 12 (1960), 287-304.

4. Nowacki, W., Thermoelasticity, Addison-Wesley, Reading (1962). 
